\title{
High Temperature Steam Corrosion of Cladding for Nuclear Applications: Experimental
}

\section{ICACC 2013}

The INL is a

U.S. Department of Energy

National Laboratory

operated by

Battelle Energy Alliance

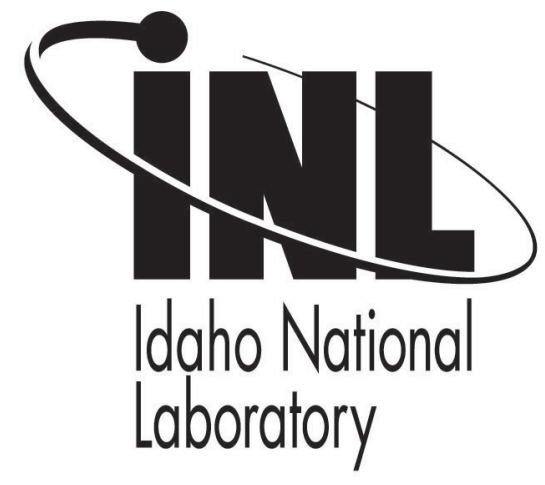

\author{
Kevin M. McHugh \\ John E. Garnier \\ Sergey Rashkeev \\ Michael V. Glazoff \\ George W. Griffith \\ Shannon M. Bragg-Sitton
}

January 2013

This is a preprint of a paper intended for publication in a journal or proceedings. Since changes may be made before publication, this preprint should not be cited or reproduced without permission of the author. This document was prepared as an account of work sponsored by an agency of the United States Government. Neither the United States Government nor any agency thereof, or any of their employees, makes any warranty, expressed or implied, or assumes any legal liability or responsibility for any third party's use, or the results of such use, of any information, apparatus, product or process disclosed in this report, or represents that its use by such third party would not infringe privately owned rights. The views expressed in this paper are not necessarily those of the United States Government or the sponsoring agency. 


\title{
HIGH TEMPERATURE STEAM CORROSION OF CLADDING FOR NUCLEAR APPLICATIONS: EXPERIMENTAL
}

Kevin M. McHugh, John E. Garnier, Sergey Rashkeev, Michael V. Glazoff, George W. Griffith, and Shannon M. Bragg-Sitton, Idaho National Laboratory, Idaho Falls, ID, USA

\begin{abstract}
Stability of cladding materials under off-normal conditions is an important issue for the safe operation of light water nuclear reactors. Metals, ceramics, and metal/ceramic composites are being investigated as substitutes for traditional zirconium-based cladding. To support downselection of these advanced materials and designs, a test apparatus was constructed to study the onset and evolution of cladding oxidation, and deformation behavior of cladding materials, under loss-of-coolant accident scenarios. Preliminary oxidation tests were conducted in dry oxygen and in saturated steam/air environments at $1000^{\circ} \mathrm{C}$. Tube samples of $\mathrm{Zr}$-702, Zr-702 reinforced with 1 ply of a $\beta$-SiC CMC overbraid, and sintered $\alpha$-SiC were tested. Samples were induction heated by coupling to a molybdenum susceptor inside the tubes. The deformation behavior of Hepressurized tubes of $\mathrm{Zr}-702$ and $\mathrm{SiC}$ CMC-reinforced $\mathrm{Zr}-702$, heated to rupture, was also examined.
\end{abstract}

\section{INTRODUCTION}

A primary requirement of advanced nuclear fuel cladding designs is to contain the nuclear fuel inside the fuel rods in the event of a loss-of-coolant accident (LOCA) without diminishing heat transfer characteristics or impairing coolant flow during normal operation. This critical function would increase the safety margin of nuclear reactor designs significantly. While Zr-based alloys are currently used as cladding in most nuclear reactor designs, a variety of advanced cladding materials including metals, ceramics and metal/ceramic composites are being considered as replacements. The corrosion behavior of these materials depends on many factors, including the chemical nature of the cladding material, the reaction temperature, and the type and concentration of the oxidizing agent. For example, corrosion of $\mathrm{Zr}$ in air follows a different oxidation pathway than it does in steam. In air, the predominant reaction is:

$$
\mathrm{Zr}(\mathrm{s})+\mathrm{O}_{2}(\mathrm{~g}) \rightarrow \mathrm{ZrO}_{2}(\mathrm{~s})
$$

In steam, oxidation is accompanied by the evolution of hydrogen gas which can potentially ignite:

$$
\mathrm{Zr}(\mathrm{s})+2 \mathrm{H}_{2} \mathrm{O}(\mathrm{g}) \rightarrow \mathrm{ZrO}_{2}(\mathrm{~s})+4 \mathrm{H}_{2}(\mathrm{~g})
$$

During a LOCA, zirconium fuel cladding can rapidly heat up to temperatures exceeding $1000^{\circ} \mathrm{C}$ due to redistribution of fuel thermal energy and fission product decay heating. Steam/cladding interactions above the $\alpha / \beta$ transformation temperature $\left(\sim 815^{\circ} \mathrm{C}\right)$ result in increased oxygen transport inside the metal, the formation of the brittle oxygen-stabilized $\alpha$ phase, and growth of a brittle $\mathrm{ZrO}_{2}$ film on the outside of the cladding. The metal can swell and rupture or fracture during refill quenching, exposing the reactor's primary coolant loop to the fuel.

A number of techniques have been developed over the years to evaluate the oxidation behavior of Zr-based cladding materials in steam and air/oxygen. Early ductility studies by 
Hobson and Rittenhouse ${ }^{1}$, and metallographic analysis by Pawel $^{2}$, led to the adoption of the $17 \%$ oxidation criterion, the $1204^{\circ} \mathrm{C}$ criterion, and Baker-Just oxidation rate correlation. ${ }^{3,4}$ These studies examined oxygen uptake above the $(\alpha+\beta) / \beta$ transformation temperature and the formation of the brittle oxygen stabilized $\alpha$ phase.

Silicon carbide exhibits excellent radiation stability, is composed of low activation elements, and retains its strength and shape under high radiation dose conditions. It is used in advanced nuclear fuel element designs to provide high thermal conductivity containment and structural support to oxide-based fuel. Tristructural Isotropic (TRISO) coated fuel particles used in gascooled reactors contain one layer of $\mathrm{SiC}$ and three layers of pyrolytic carbon surrounding the fuel kernel. Here the $\mathrm{SiC}$ acts as a pressure vessel for fission products, providing structural integrity while retaining solid fission products inside the fuel pellet. ${ }^{5} \mathrm{All}-\mathrm{SiC}$ fuel rod cladding designs are in the development and testing stage for use in light water reactors. ${ }^{6} \mathrm{Zr}$-based fuel rods overbraided with $\mathrm{SiC}$ ceramic matrix composites could also provide additional structural support, increasing the margin of safety of the metal fuel rods (Figure 1). ${ }^{7}$

$\mathrm{SiC}$ is more stable than $\mathrm{Zr}$ in air and steam environments, and provides the potential for greater structural stability in a LOCA. Researchers have studied the corrosion behavior of high purity $\mathrm{CVD} \mathrm{SiC}$ in steam and oxygen and have found that corrosion behavior differs substantially. ${ }^{8}$ Corrosion in dry oxygen involves the formation of a relatively stable $\mathrm{SiO}_{2}$ layer:

$$
2 \mathrm{SiC}(\mathrm{s})+3 \mathrm{O}_{2}(\mathrm{~g}) \rightarrow 2 \mathrm{SiO}_{2}+2 \mathrm{CO}(\mathrm{g})
$$

Further oxidation is limited by the oxygen diffusion rate through silica. This layer thus protects the underlying $\mathrm{SiC}$, as the diffusion rate is low. In contrast, the introduction of water vapor allows hydrolysis of $\mathrm{SiO}_{2}$ to occur, and corrosion of $\mathrm{SiC}$ proceeds more rapidly following a twostep oxidation/volatilization reaction"

$$
\begin{aligned}
& \mathrm{SiC}(\mathrm{s})+3 \mathrm{H}_{2} \mathrm{O}(\mathrm{g})=\mathrm{SiO}_{2}(\mathrm{~s})+3 \mathrm{H}_{2}(\mathrm{~g})+\mathrm{CO}(\mathrm{g}) \\
& \mathrm{SiO}_{2}(\mathrm{~s})+2 \mathrm{H}_{2} \mathrm{O}(\mathrm{g})=\mathrm{Si}(\mathrm{OH})_{4}(\mathrm{~g})
\end{aligned}
$$

Since the $\mathrm{Si}(\mathrm{OH})_{4}$ is volatile, the recession rate of $\mathrm{SiC}$ is greater. The kinetics of the oxidation reaction are described by a parabolic rate constant, while the kinetics of volatilization are described by a linear rate constant. As the partial pressure of water vapor increases, the corrosion rate increases. ${ }^{10}$ The $\mathrm{SiC}$ recession rate accelerates with rising temperature.

The potential benefits of advanced ceramic and composite materials in the design of nuclear reactor components underscores the need to contrast corrosion behavior of these materials with conventional zirconium-based materials in LOCA scenarios under identical test conditions. 

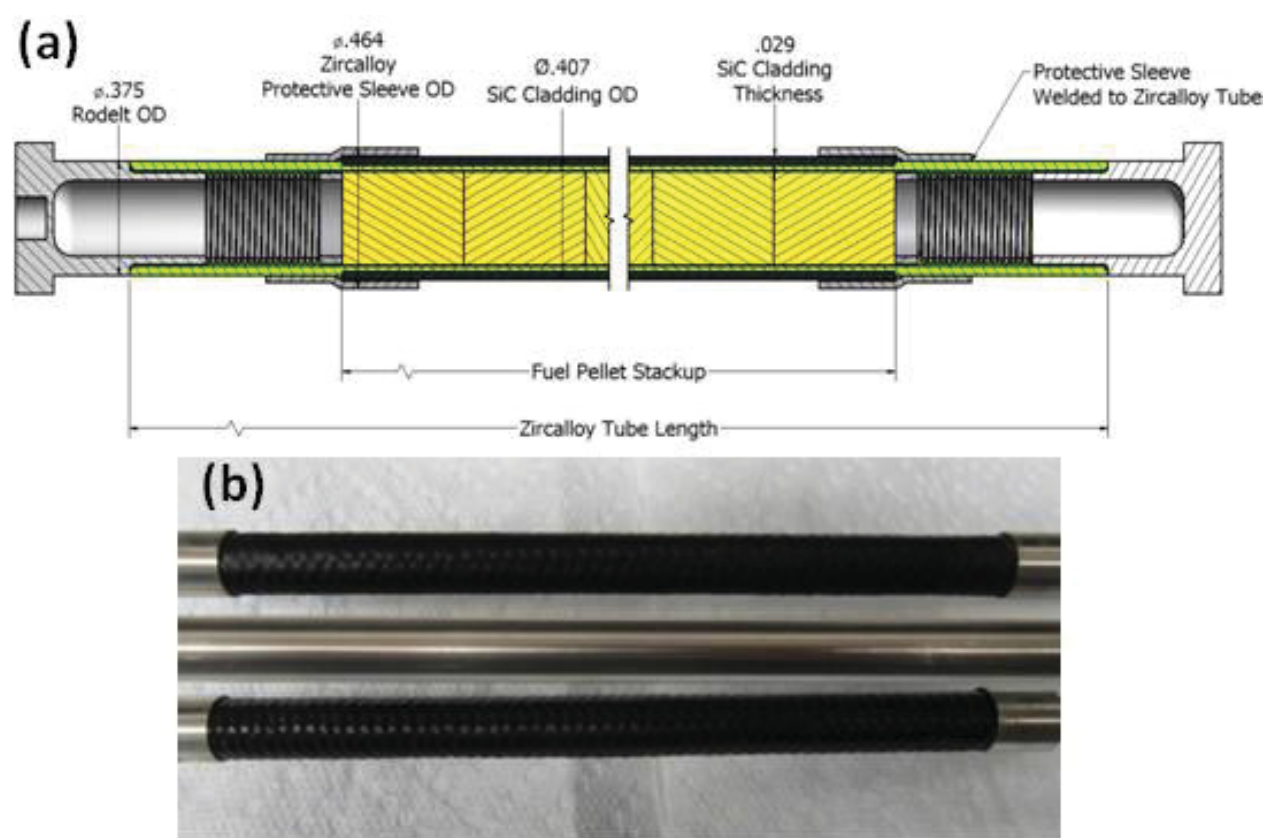

Figure 1. (a) Cladding assembly design, and, (b) fabricated samples of Zircaloy-4 overbraided with 1-ply and 2-ply $\mathrm{SiC} / \mathrm{SiC}$ ceramic matrix composites (CMCs). ${ }^{11}$

\section{EXPERIMENTAL}

The test apparatus used in this study, referred to as the Oxidation Kinetics System (OKS), has been described previously. ${ }^{12}$ The system tracks and catalogs outputs from various pressure, temperature and gas composition sensors while exposing heated fuel cladding samples to water/steam, water/air or other oxidation environments. One-color and two-color pyrometers, in conjunction with a thermal image system and thermocouple signals, track the onset of oxidation via emissivity changes at the surface of the cladding. These instruments also sense the exothermic/endothermic reactions that accompany oxidation and phase changes. Gas-phase reaction products of oxidation (e.g., $\mathrm{H}_{2}$ and $\mathrm{CO}$ ) are monitored and correlated with temperature/emissivity changes. In addition, nonvolatile or water-soluble oxidation products are collected in a condenser and evaluated off-line.

Te following samples were oxidized in air that was saturated with steam inside a sealed chamber:

1. Closed $\mathrm{Zr}-702$ tubes, pressurized with $\mathrm{He}$ to $3.4 \mathrm{MPa}$ and heated at a rate of $37^{\circ} \mathrm{C} / \mathrm{min}$ to bursting.

2. Closed Zr-702 tubes with 1" sleeves of 1 ply $\mathrm{SiC} / \mathrm{SiC}$ CMC. These composite tubes were pressurized with $\mathrm{He}$ to $3.4 \mathrm{MPa}$ and heated to bursting at a rate of $37^{\circ} \mathrm{C} / \mathrm{min}$.

3. Open tubes of $\mathrm{Zr}-702$ heated to $1000^{\circ} \mathrm{C}$ at a rate of $37^{\circ} \mathrm{C} / \mathrm{min}$ and held for one hour.

Additional samples were tested in dry oxygen. These samples were heated at a rate of about $5^{\mathrm{O}} \mathrm{C} / \mathrm{min}$ in argon to $1000^{\circ} \mathrm{C}$ and exposed to dry oxygen for 10 minutes:

1. Open tubes of sintered $\alpha$-SiC.

2. Open tubes of $\mathrm{Zr}-702$.

The Zr-702 tubes were vertically oriented and fixed at one end. The other end was attached to a pressurized helium gas source via a flexible stainless steel 316L gas line. Helium used to 
pressurize the samples was ultra high purity. High purity dry oxygen was used in the dry oxygen experiments. High purity (nanopure) water having chemistry characteristics similar to the primary coolant loop of INL's Advanced Test Reactor (ATR) was used to generate steam inside the closed system. The water's $\mathrm{pH}=5.1$, dissolved oxygen $=5.5 \mathrm{ppm}$, and conductivity $=3.2$ $\mu \mathrm{S} / \mathrm{cm}$ were measured using temperature compensated probes for $\mathrm{pH}$ (Rosemont Analytical 3500VP sensor), dissolved oxygen (Rosemont Analytical HX438 sensor) and conductivity (Rosemont Analytical 400 sensor).

The CMCs were fabricated by polymer infiltration and pyrolysis (PIP) of a 1-ply woven fabric of Hi Nicalon using polycarbosilane. ${ }^{13}$ Both the fibers and the matrix were $\beta-\mathrm{SiC}$. Commercial pressureless-sintered $\alpha$-SiC tube samples were formed from $\sim 6 \mu \mathrm{m}$ power to $98 \%$ density using boron and carbon sintering aids. ${ }^{14}$ Figure 2 compares the surface appearance of the $\mathrm{SiC}$ samples used in this study.

(a)

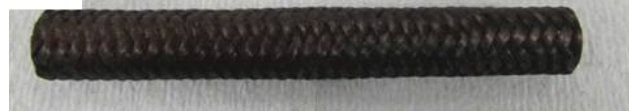

(b)

Figure 2. SiC tube samples used in this study. (a) CMC sleeve formed from woven $\beta$-SiC fibers that was used to reinforce $\mathrm{Zr}-702$ tubes during deformation testing. (b) $\alpha$-SiC tube.

Commercial Zr-702 tubes (Zircadyne ${ }^{\mathrm{TM}}$ 702, UNS Designation R60702) measuring 9.5 mm OD x $7.6 \mathrm{~mm}$ ID x $356 \mathrm{~mm}$ were used. ${ }^{15}$ The alloy contains up to $4.5 \mathrm{wt} . \%$ Hf in solid solution, with the following maximum limits of other elements: $\mathrm{Fe}+\mathrm{Cr}(0.20 \%), \mathrm{H}(0.005 \%), \mathrm{N}$ $(0.025 \%), \mathrm{C}(0.05 \%)$, and $\mathrm{O}(0.16 \%)$. While the Hf content of the alloy precludes its use in a nuclear reactor, it was chosen due to cost and availability for these preliminary studies.

Samples were induction heated from the inside-out by coupling to a $7.5 \mathrm{~mm} \mathrm{OD} \mathrm{x} 254$ $\mathrm{mm}$ long molybdenum rod placed inside the tubes. The gap between the Mo and cladding was chosen to be similar to the gap between fuel pellets and cladding in a typical pressurized water reactor (PWR). Temperature was measured using type $\mathrm{K}$ thermocouples placed $25 \mathrm{~mm}$ inside the Mo susceptor, as well as at the center of the $\mathrm{Zr}$ tube and $50 \mathrm{~mm}$ above the center of the tube.

\section{RESULTS AND DISCUSSION}

Oxidation in steam/air and dry oxygen at $1000^{\circ} \mathrm{C}$. $1000^{\mathrm{O}} \mathrm{C}$.

Figure 3 illustrates the surface oxidation of $\mathrm{Zr}-702$ tubing after one hour exposure to steam/air at
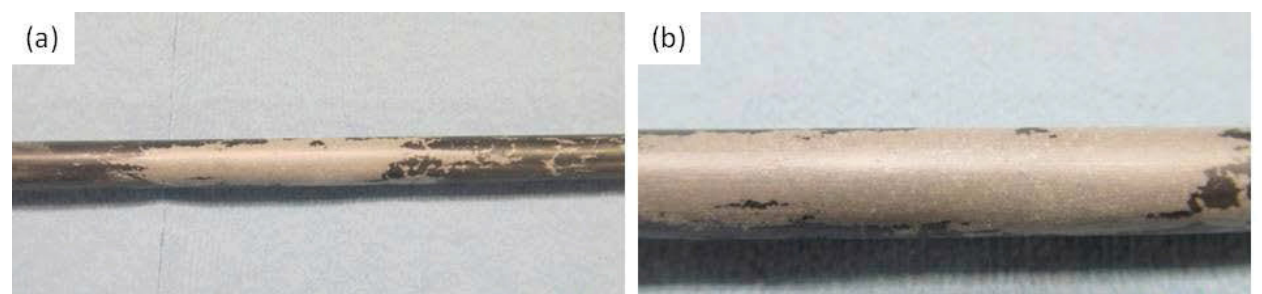

Figure 3. Surface oxidation of Zr-702 tubing following one hour exposure to steam/air at $\sim 1000^{\circ} \mathrm{C}$.

The mottled surface was characterized by a white, flaky, fully-converted $\mathrm{ZrO}_{2}$ product and a tenacious black transitional zirconium oxide layer. Tube samples were sectioned along the length at $25 \mathrm{~mm}$ increments from the center of the tube to the edge of the induction heated zone $(254 \mathrm{~mm})$. Similar 
microstructure features were observed for all samples. Figure 4 shows representative SEM photomicrographs of the cross-section of tubing, at various magnifications. Three main microstructure zones were observed as oxygen diffuses into the alloy at $1000^{\circ} \mathrm{C}$ : an outer, fully-converted zirconium oxide layer; a partially converted underlying zone of oxygen-stabilized $\alpha$-Zr phase; and a minimally oxidized $\beta$-Zr phase of the base metal. The fully converted zirconium oxide layer was about $65 \mu \mathrm{m}$ thick and was interlaced with axial and transverse cracks of various lengths that resulted from tensile loading due to volumetric expansion. Use of a vCD detector (BSE mode) in Figure 4d clearly revealed these cracks as well as transverse cracks which initiated in the brittle, oxygen-stabilized, $\alpha$-Zr phase of the metal. The oxygen-stabilized, $\alpha-Z r$ phase was less well resolved but appeared to be about $30 \mu \mathrm{m}$ thick. Similar trends have been observed by other investigators in steam-oxidized Zircaloy-2 ${ }^{4,18}$ and Zircaloy4. ${ }^{16,17,19}$ The relative thickness of the fully converted oxide layer and O-stabilized $\alpha$ phase will depend on temperature and time. Weight gain measurements in these studies indicated that the total oxygen uptake for samples tested at $1000^{\circ} \mathrm{C}$ obeys a parabolic rate law, $\mathrm{W}^{2}=\mathrm{K}_{\mathrm{p}} \mathrm{t}$ where $\mathrm{K}_{\mathrm{p}}$ is the temperature dependent rate constant, $\mathrm{W}$ denotes oxygen weight gain, and $\mathrm{t}$ is time. The current study was conducted in acidified steam (simulating a LOCA at INL's ATR reactor). It is not clear to what extent this affected the oxidation behavior.
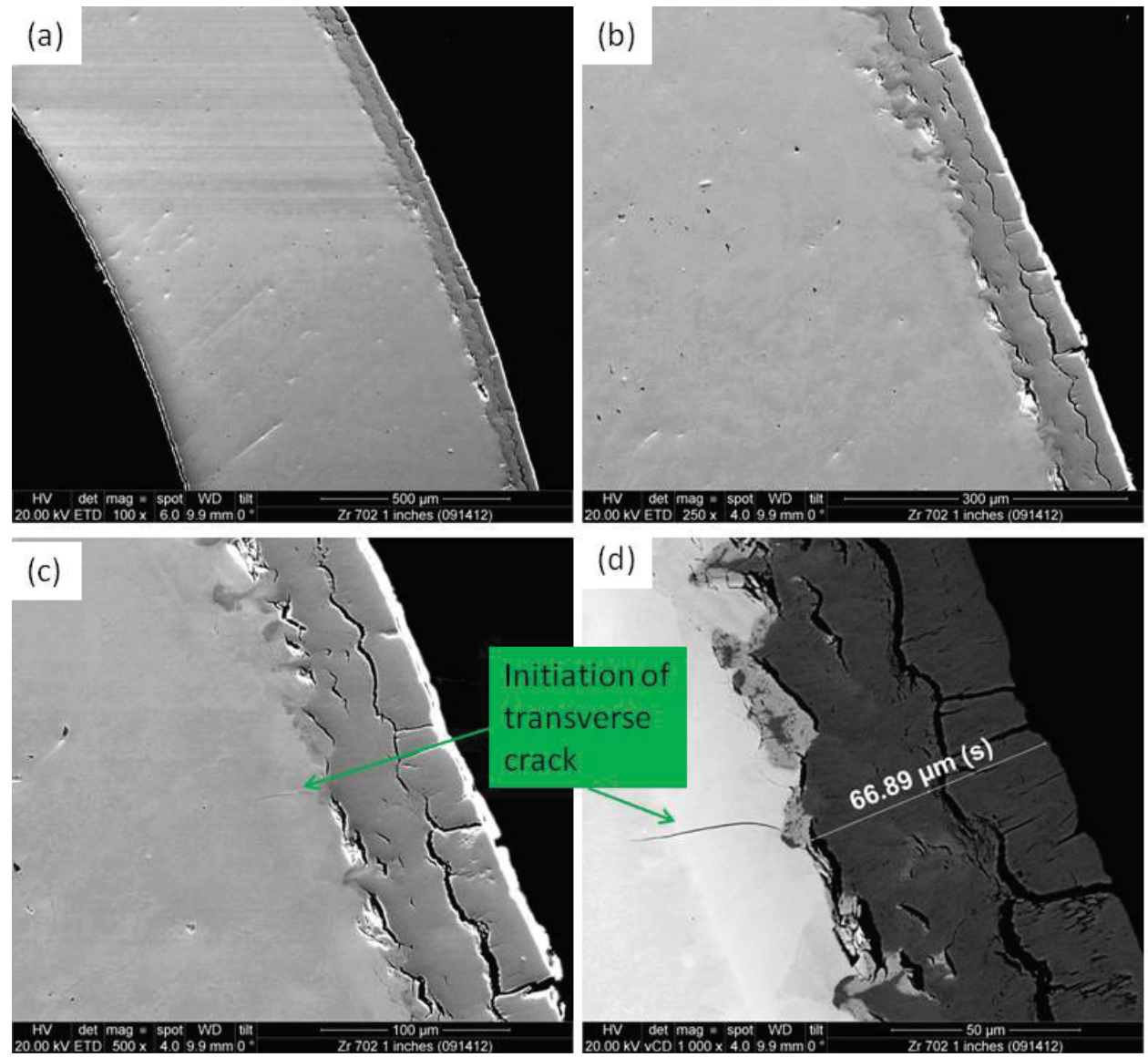

Figure 4. SEM photomicrographs of Zr-702 tubing following one hour exposure in air/supersaturated steam at $\sim 1000^{\circ} \mathrm{C}$. (a) $100 \mathrm{X}$, secondary electron mode. (b) $250 \mathrm{X}$, secondary electron mode. (c) $500 \mathrm{X}$, secondary electron mode. (d) 1000X, backscattered electron mode.

EDS element mapping analysis was performed on a cross-section of oxidized tubing to determine the transition in composition from the outer edge of the tube to the interior. Nine scans, each 2.5 $\mathrm{min} / \mathrm{scan}$, and evenly spaced by $14.6 \mu \mathrm{m}$, were taken progressing from the center of the oxide layer to about $117 \mu \mathrm{m}$ into the interior of the sample. Figure 5 summarizes concentration data of $\mathrm{O}, \mathrm{Zr}, \mathrm{Cr}, \mathrm{Fe}$, and Hf. 


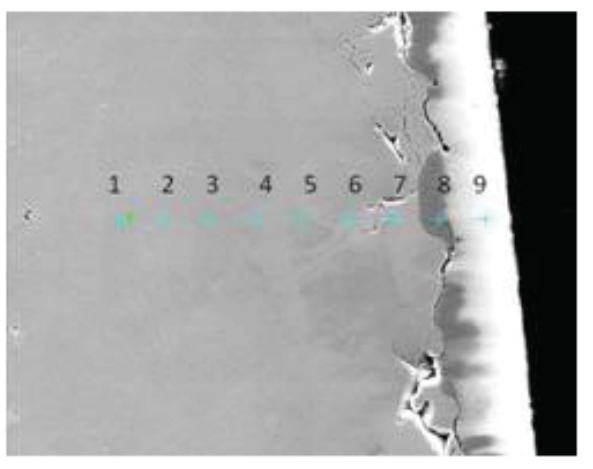

\begin{tabular}{|c|c|c|c|c|c|}
\hline Spot\# & $\begin{array}{c}\mathrm{O} \\
(\text { wt\%) }\end{array}$ & $\begin{array}{c}\mathrm{Zr} \\
(\text { wt \%) }\end{array}$ & $\begin{array}{c}\mathrm{Cr} \\
(\text { wt \%) }\end{array}$ & $\begin{array}{c}\mathrm{Fe} \\
(\text { wt \%) }\end{array}$ & $\begin{array}{c}\text { Hf } \\
(\text { wt \%) }\end{array}$ \\
\hline 1 & 0.83 & 92.3 & 0.32 & 0.34 & 2.13 \\
\hline 2 & 0.79 & 92.1 & 0.37 & 0.43 & 2.12 \\
\hline 3 & 1.14 & 92.08 & 0.32 & 0.38 & 2.00 \\
\hline 4 & 1.33 & 91.78 & 0.32 & 0.42 & 1.79 \\
\hline 5 & 1.87 & 91.11 & 0.35 & 0.40 & 2.08 \\
\hline 6 & 2.60 & 90.75 & 0.30 & 0.37 & 1.88 \\
\hline 7 & 3.17 & 90.16 & 0.30 & 0.36 & 1.86 \\
\hline 8 & 14.37 & 79.71 & 0.21 & 0.27 & 1.43 \\
\hline 9 & 14.98 & 79.79 & 0.03 & 0.12 & 1.17 \\
\hline
\end{tabular}

Figure 5. EDS element probe data taken on a Zr-702 sample following one hour exposure to air/supersaturated steam at $\sim 1000^{\circ} \mathrm{C}$. (a) SEM photomicrograph showing sampling locations. (b) Wt.\% data for $\mathrm{O}, \mathrm{Zr}, \mathrm{Cr}, \mathrm{Fe}$ and $\mathrm{Hf}$ at various sampling locations.

There is a steep drop in the oxygen concentration from the largely converted $\mathrm{ZrO}_{2}$ to the O-stabilized $\alpha$ $\mathrm{Zr}$. This is followed by a gradual decrease in the prior $\beta-\mathrm{Zr}$ region of the interior. The concentrations of $\mathrm{Cr}, \mathrm{Fe}$, and $\mathrm{Hf}$ in these regions follow a similar pattern. As the layer of O-stabilized $\alpha-\mathrm{Zr}$ grows, $\beta$ stabilizing elements such as $\mathrm{Cr}$ and Fe preferentially diffuse into the $\beta$-Zr phase at a high diffusion rate.

Additional samples of $\mathrm{Zr}-702$ and sintered $\alpha$-SiC were heated to $1000^{\circ} \mathrm{C}$ in argon and then exposed to high purity, dry oxygen for 10 minutes. Figure 6 compares the microstructures near the edge of a $\mathrm{Zr}-702$ tube (Figure 6a) and pressureless sintered $\alpha$-SiC (Figure 6b). The Zr-702 sample formed a brittle $\mathrm{ZrO}_{2}$ layer at the exposed surface measuring about $40 \mu \mathrm{m}$ thick. Both axial and transverse cracks are present, along with evidence of spalling and delamination. The adjacent oxygen-stabilized $\alpha-\mathrm{Zr}$ phase is also about $40 \mu \mathrm{m}$ thick and appears to be uniform in thickness. Transverse cracks are seen in this layer. Optical microscopy also reveals significant coarsening of the $\beta$-Zr phase in the interior of the sample due to the slow heating rate. The $\alpha$-SiC sample (Figure 6b) has formed a relatively thin layer of $\mathrm{SiO}_{2}$ that appears to be of variable thickness.
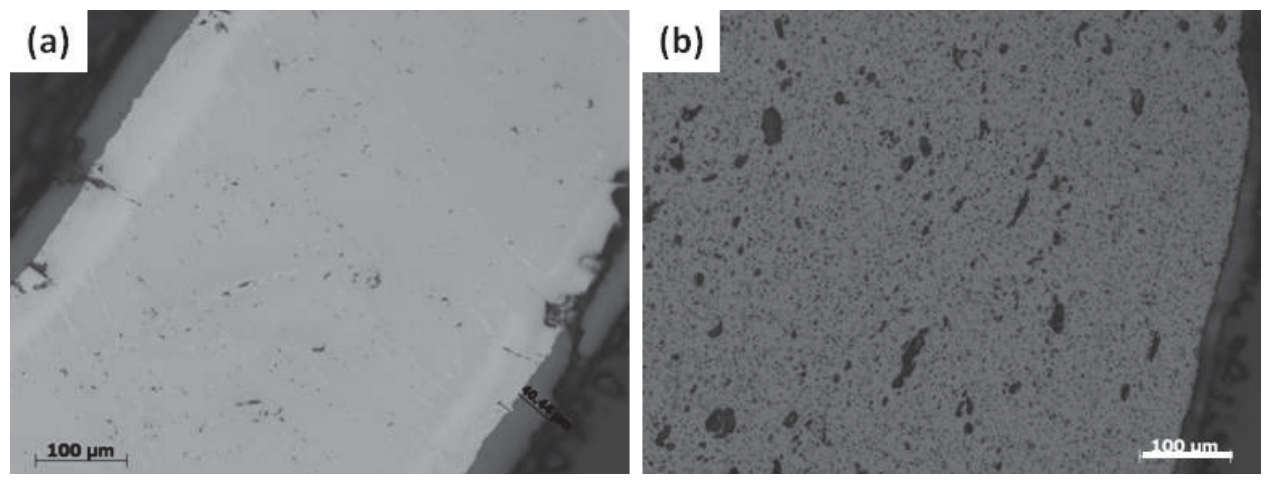

Figure 6. Optical photomicrographs of (a) Zr-702, and, (b) pressureless sintered $\alpha$-SiC following a 10 minute exposure to dry oxygen at $1000^{\circ} \mathrm{C}$.

Figure 7 compares the microstructure of etched Zr-702 samples viewed with polarized light. The starting material, shown in Figure $7 \mathrm{a}$, is characterized by a uniform, relatively fine-grained $\alpha$-Zr phase, with small, uniformly distributed second- phase particles. During oxidation at $1000^{\circ} \mathrm{C}$ in steam (Figure $7 \mathrm{~b}$ ) or oxygen (Figure 7c), a relatively coarse O-stabilized $\alpha-Z r$ phase formed. A sharp interface forms with the $\beta-\mathrm{Zr}$ because $\beta$ phase stabilizers such as $\mathrm{Fe}$ and $\mathrm{Cr}$ diffuse into the $\beta-\mathrm{Zr}$, as shown in Figures $7 \mathrm{~b}$ and $7 \mathrm{c}$. The slow heating rate for the sample oxidized in dry oxygen caused the $\beta-Z r$ phase to coarsen. 

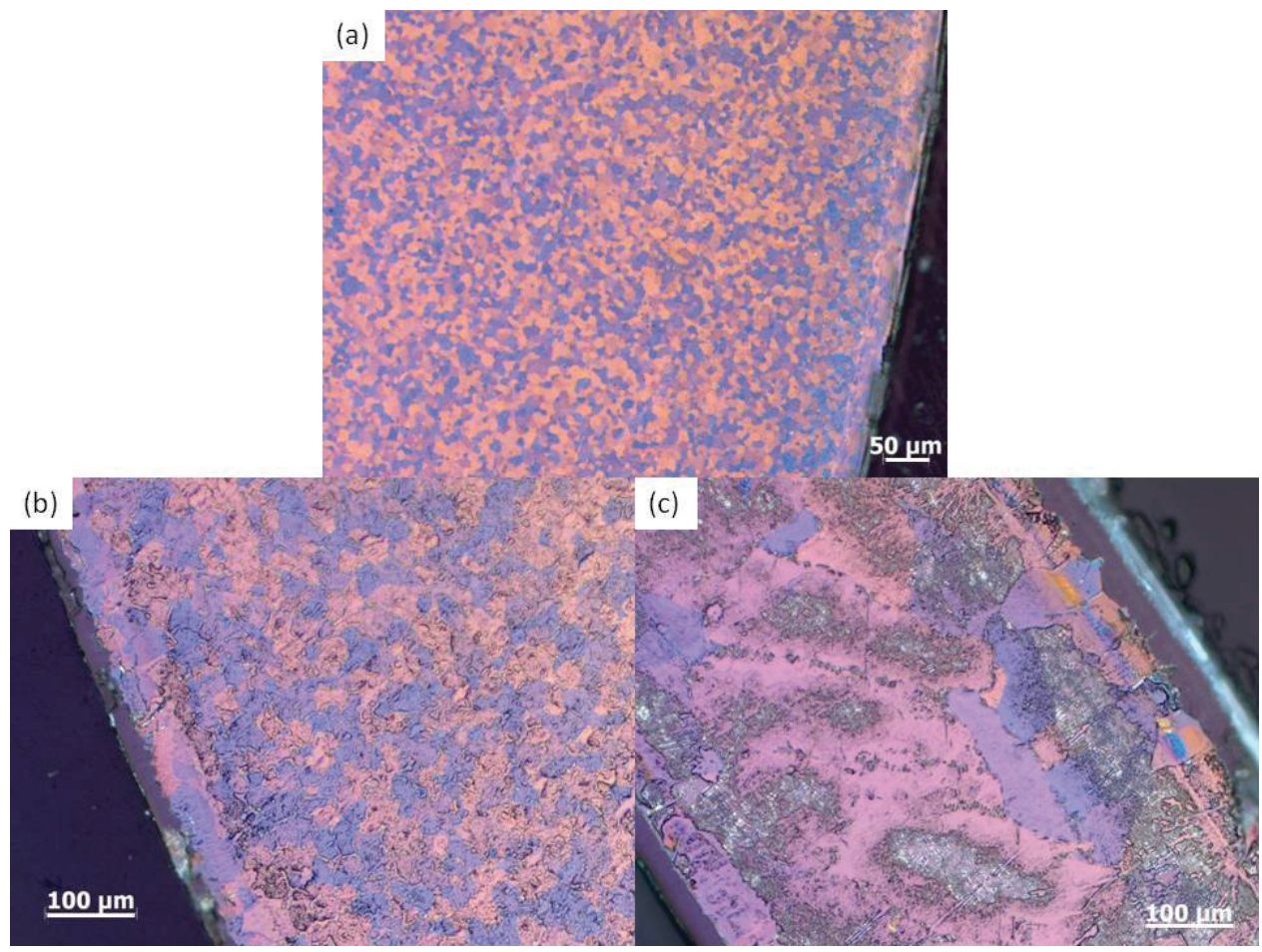

Figure 7. Optical photomicrographs of etched Zr-702 tubing cross sections viewed with polarized light. (a) As-received commercial tubing. (b) Oxidized in steam/air. (c) Oxidized in dry oxygen.

Deformation of pressurized tubes

Nuclear fuel rods used in a PWR are internally pressurized with He to about $2 \mathrm{MPa}$ during manufacture. Helium is added to improve thermal conductivity at the pellet-cladding interface, and to reduce interaction between pellet and cladding during service. As the tubes are heated, the pressure rises. As the fuel ages, gaseous fission products further increase the pressure. The internal pressure is largely offset by the water pressure in the reactor's primary coolant loop. During a LOCA, as primary coolant is lost, the rise in differential pressure can cause the cladding to strain and rupture. Advanced materials such as SiC CMC could increase the reactor's safety margin by providing containment for the nuclear fuel, preventing it from entering the primary coolant.

Deformation of fuel cladding during a LOCA is very complicated. Stress, temperature, and creep strength influence deformation. Azimuthal (circumferential) temperature variations due to fuel movement and eccentricity can play an important role in local temperature and strain behavior. Manufacturing flaws and small differences in microstructure also influence creep. Various studies have been conducted worldwide to study the deformation and ballooning behavior of zirconium alloys in steam, for example, at the PROPAT facility in the $\mathrm{UK}^{20}$, the EDGAR- ${ }^{21}$ and EDGAR-22 ${ }^{22}$ facilities in Canada and at CEA in France, the Korean Atomic Energy Institute ${ }^{23}, \mathrm{Japan}^{24}$, and elsewhere.

Preliminary experiments were conducted in steam/air on pressurized tubes of $\mathrm{Zr}-702$ measuring $9.5 \mathrm{~mm}$ OD x $356 \mathrm{~mm}$ long. As-received Zr-702 tubes and $\mathrm{Zr}-702$ tubes reinforced with a $\sim 38 \mathrm{~mm}$ long tubular sleeve of $\mathrm{SiC} \mathrm{CMC}$, as shown in Figure 2a, were tested. The composite tube consisted of single-ply Hi Nicalon $\beta$-SiC woven fibers that were polymerinfiltrated with polycarbosilane and pyrolyzed to form a matrix of $\beta$-SiC. Tubes were pressurized 
with He to $3.4 \mathrm{MPa}$ and induction heated to the point of rupture by coupling the induction field to a $254 \mathrm{~mm}$ long Mo rod susceptor inserted inside the $\mathrm{Zr}-702$ tubes at the center. Temperature of the susceptor was monitored with a grounded type $\mathrm{K}$ thermocouple inserted $25 \mathrm{~mm}$ from the end of the susceptor. Tubes were heated at an average rate of $37^{\mathrm{O}} \mathrm{C} / \mathrm{min}$.

Figure 8a shows an as-received (starting) Zr-702 tube, and ruptured sample, while Figure 8 b shows a starting Zr-702 tube with a $11 \mathrm{~mm}$ ID x $11.3 \mathrm{~mm}$ OD x $38 \mathrm{~mm}$ long SiC CMC sleeve. The sleeve fit loosely over the $\mathrm{Zr}-702$ tube with about $1.5 \mathrm{~mm}$ clearance. Since the tubes were vertically oriented, a small ring of a $\mathrm{ZrO}_{2}$-based adhesive was applied to the $\mathrm{Zr}$ - 702 tube to center the $\mathrm{SiC} \mathrm{CMC} \mathrm{sleeve} \mathrm{and} \mathrm{hold} \mathrm{it} \mathrm{in} \mathrm{place.} \mathrm{The} \mathrm{coating} \mathrm{ring} \mathrm{appears} \mathrm{white} \mathrm{in} \mathrm{Figure} 8 \mathrm{~b}$, to the left of the SiC CMC.
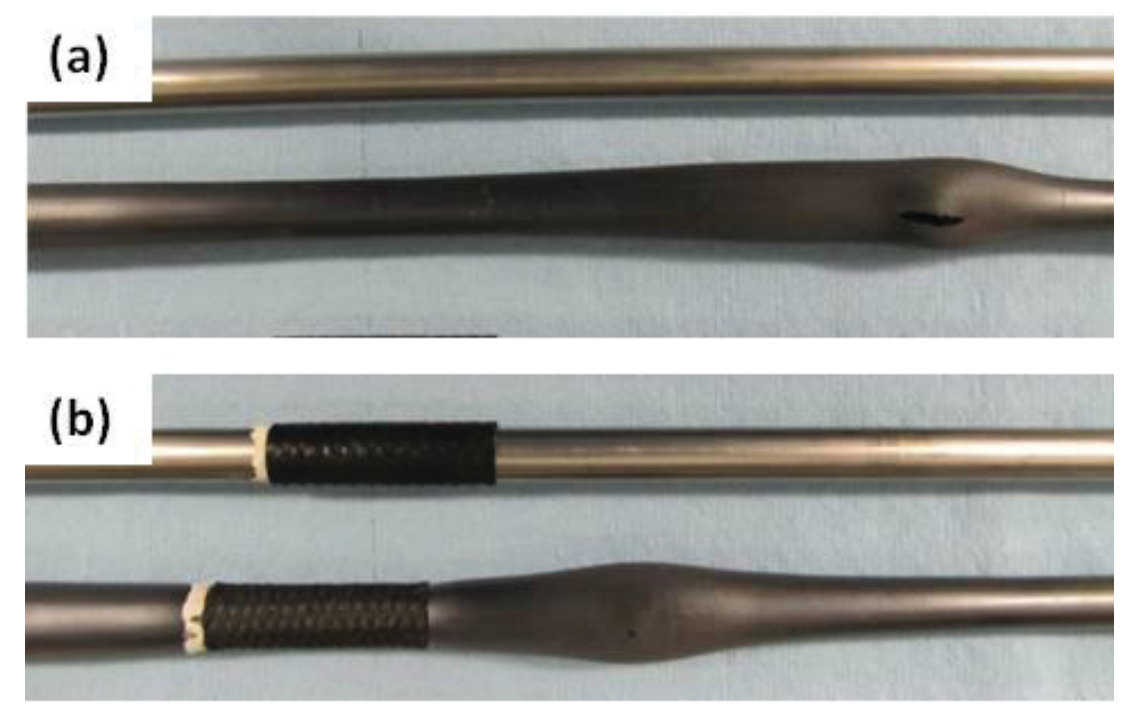

Figure 8. Photographs of starting samples (above) and ruptured samples (below) of (a) Zr-702 tube, and, (b) Zr-702 tube fitted with a SiC CMC sleeve.

Rupture of the unreinforced tube occurred at about $850^{\circ} \mathrm{C}, 13 \mathrm{~mm}$ from the center of the tube, and was accompanied by a loud popping sound of tearing metal and rapid pressure drop (Figure 9a). A second unreinforced tube ruptured at $896^{\circ} \mathrm{C}, 93 \mathrm{~mm}$ from the center of the tube (Figure 8a). The metal samples ballooned and ruptured in a similar way, with axial tears measuring about $17 \mathrm{~mm}$ and $10 \mathrm{~mm}$, respectively. Swelling was observed along the entire length of the tube. $\mathrm{Zr}-702$ in the HCP structure ( $\alpha$ phase) transforms to the BCC structure ( $\beta$ phase) at $865^{\circ} \mathrm{C}$. The presence of $\beta$ phase reduces the strength substantially. Similar results have been observed with rupture tests conducted on Zircaloy cladding metal tubes, i.e., rupture occurs as the metal transitions into the $\alpha+\beta$ phase field.

Identical experimental conditions were used to evaluate two samples reinforced with 1ply SiC CMC sleeves. The samples ruptured at somewhat higher temperatures, about $920^{\circ} \mathrm{C}$ and $914^{\mathrm{O}} \mathrm{C}$. The ruptured area of the reinforced samples was small and pin-hole shaped, and was accompanied by a somewhat slower, inaudible release of pressure. The ruptures occurred $5 \mathrm{~mm}$ and $7 \mathrm{~mm}$ from the center of the tubes, respectively. Notable swelling occurred along the length of the Zr-702 tube except where the tube was reinforced with the SiC CMC sleeve. 
Dimensional data for two deformed tubes, one with and one without a reinforcing $\mathrm{SiC}$ CMC sleeve, are given in Figures 9 and 10. Diameters were measured in line with the location of the rupture (Figure 9) and at a $90^{\circ}$ rotation (Figure 10) for the same samples. Swelling occurred along the entire length of the tubes where they were internally heated. The samples ballooned at the location of the rupture with a maximum circumferential strain of about $80 \%$. This is significant considering that the spacing of fuel rods in a typical PWR design is such that adjacent rods strained by about $32 \%$ will touch. At the location of the reinforcing SiC CMC sleeve, metal expansion was significantly constrained. The OD increased about $2 \%$, indicating the 1-ply braided $\mathrm{SiC} \mathrm{CMC} \mathrm{fabric} \mathrm{stretched} \mathrm{slightly} \mathrm{but} \mathrm{did} \mathrm{not} \mathrm{fail} \mathrm{under} \mathrm{the} \mathrm{test} \mathrm{conditions.}$

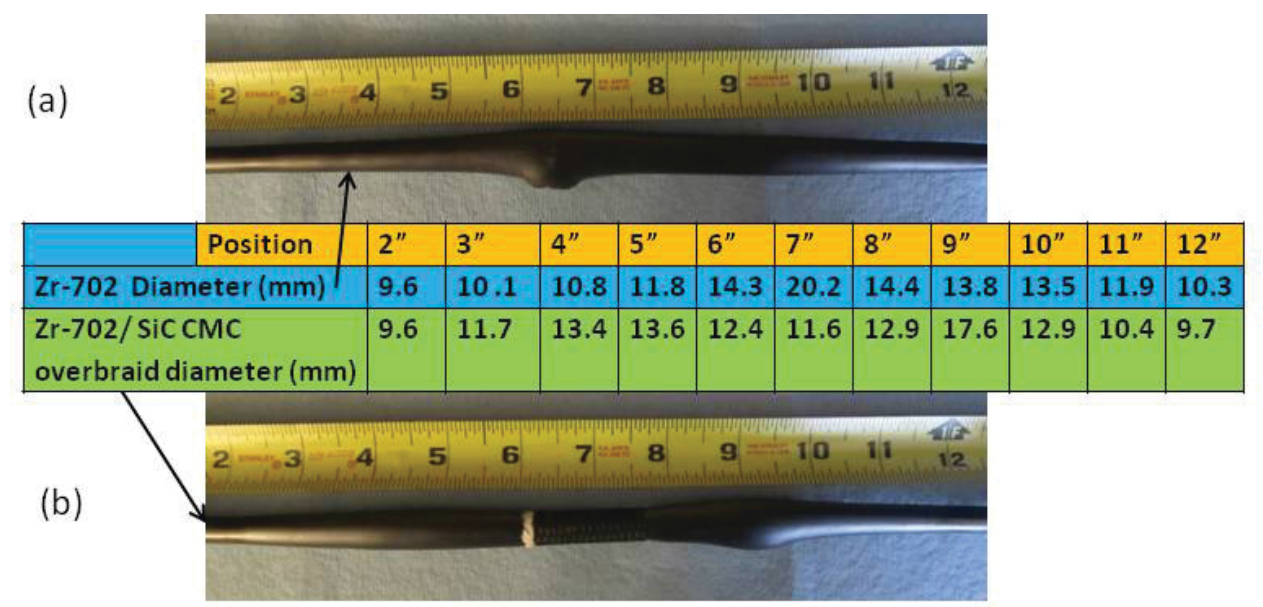

Figure 9. Dimensional data for ruptured Zr-702 tubes. Diameter measurements were made inline with the location of the rupture. (a) Unreinforced $\mathrm{Zr}-702$ tube. (b) $\mathrm{Zr}-702$ tube reinforced with a $38 \mathrm{~mm}$ long $\mathrm{x} 11.3 \mathrm{~mm}$ OD SiC CMC sleeve at the center. 


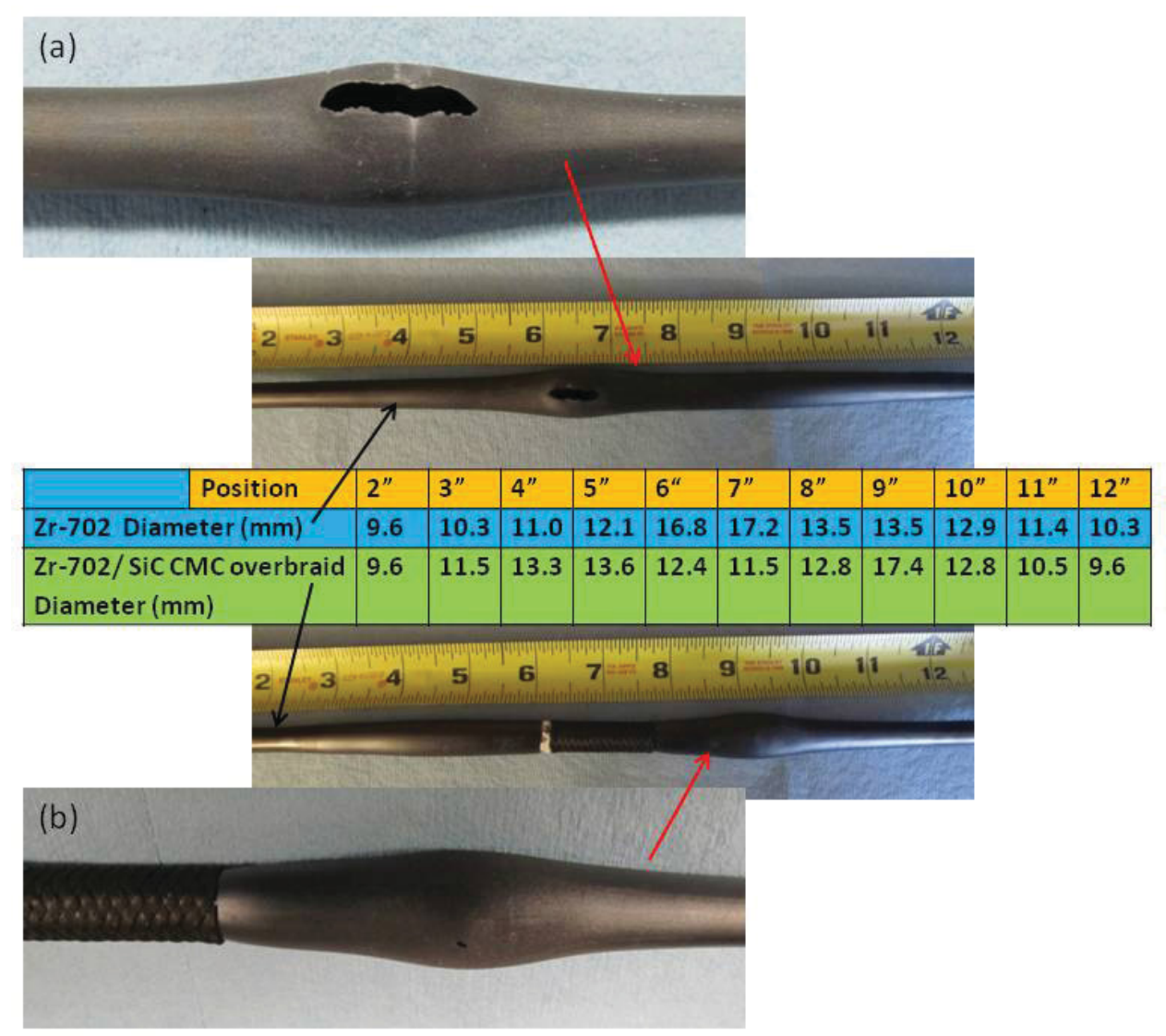

Figure 10. Dimensional data for ruptured Zr-702 tubes. Diameter measurements were made at $90^{\circ}$ rotation to the location of the rupture. (a) Unreinforced $\mathrm{Zr}-702$ tube. (b) $\mathrm{Zr}-702$ tube reinforced with a $38 \mathrm{~mm}$ long $x 11.3 \mathrm{~mm}$ OD SiC CMC sleeve at the center. Expanded views at the rupture locations are shown.

\section{CONCLUSIONS}

A newly designed test apparatus referred to as the Oxidation Kinetics System (OKS) was used in this study. The system exposes nuclear fuel cladding materials to out-of-reactor, simulated LOCA conditions to study the onset and evolution of oxidation, deformation behavior and quenching behavior.

Preliminary tests were conducted using $\mathrm{Zr}-702$ and $\mathrm{SiC}$ ceramic materials. The $\mathrm{SiC}$ materials were sintered $\alpha-\mathrm{SiC}$ and a $\beta-\mathrm{SiC} / \beta-\mathrm{SiC}$ CMC composed of Hi Nicalon fibers in a matrix of pyrolyzed polycarbosilane. As expected, $\mathrm{SiC}$ exhibited improved oxidation resistance over Zr-702 in dry oxygen and steam/air at $1000^{\circ} \mathrm{C}$. Oxygen and steam readily attacked Zr-702 forming a brittle $\mathrm{ZrO}_{2}$ layer at the exposed surface interlaced with axial and transverse cracks. Oxygen diffusion through this layer resulted in the formation of an oxygen-stabilized $\alpha-\mathrm{Zr}$ phase with intermittent transverse cracks. The interior of the $\mathrm{Zr}-702$ transformed to the $\beta-\mathrm{Zr}$ phase which coarsened with exposure time at elevated temperature. The $\mathrm{SiC}$ materials formed a thin layer of relatively stable $\mathrm{SiO}_{2}$.

Preliminary experiments were also conducted in steam/air on pressurized (3.4 MPa $\mathrm{He})$ tubes of Zr-702 and Zr-702 tubes reinforced with a tubular sleeve of SiC CMC. The tubes were induction heated to the point of rupture by coupling the induction field to a Mo susceptor inserted inside the $\mathrm{Zr}-702$ tubes. Rupture occurred as the $\mathrm{Zr}-702$ transitioned into the $\alpha+\beta$ phase 
field. Ballooning was observed for all samples with a maximum circumferential strain of about $80 \%$. At the location of the reinforcing $\mathrm{SiC}$ CMC sleeve, metal expansion was significantly constrained. The OD increased about $2 \%$, indicating the 1-ply braided SiC CMC fabric stretched but did not fail under the test conditions.

\section{ACKNOWLEDGEMENT}

The authors gratefully acknowledge contributions of Matt Weseman, Tammy Trowbridge, Todd Morris (INL) and Jesse Johns (Texas A\&M University). This work was supported by the U.S. Department of Energy, Office of Nuclear Energy, under DOE Idaho Operations Office Contract DE-AC07-05ID14517.

\section{REFERENCES}

${ }^{1}$ D. O. Hobson and P. L. Rittenhouse, "Embrittlement of Zircaloy-Clad Fuel Rods by Steam During LOCA Transients," Oak Ridge National Laboratory, ORNL-4758, January, 1972.

2 R. E. Pawel, "Oxygen Diffusion in $\beta$ Zircaloy During Steam Oxidation," J. Nucl.Mater. 50 (1974) 247-258.

${ }^{3}$ L. Baker, Jr. and L.C. Just, "Studies of Metal-Water Reactions at High Temperatures. III. Experimental and Theoretical Studies of the Zirconium-Water Reaction," Argonne National Laboratory, ANL 6548, May 1962.

4 A. F. Brown and T. Healey, "The Kinetics of Total Oxygen Uptake in Steam-Oxidized Zircaloy-2 in the Range 1273-1673 K," J. Nucl.Mater. 88 (1980) 1-6.

${ }^{5}$ Lance L. Snead, Takashi Nozawa, Yutai Katoh, Thak-Sang Byun, Sosuke Kondo, and David A. Petti, "Handbook of SiC properties for fuel performance modeling," J. Nucl. Mater. 371 (2007) 329-377.

${ }^{6}$ Herbert Feinroth and Bernard R. Hao, "Multi-layered ceramic tube for fuel containment barrier and other applications in nuclear and fossil power plants," Westinghouse Electric, July 2006: WO 2006/076039.

7 John E. Garnier and George W. Griffith, "Cladding Material, Tube Including Such Cladding Material and Methods of Forming the Same," U. S. Patent Application Attorney Docket 293910060US (BA-477).

${ }^{8}$ Nathan Jacobson, Dwight Myers, Elizabeth Opila and Evan Copland, "Interactions of Water Vapor with Oxides at Elevated Temperatures," J. Phys. Chem. Solids 66 (2005) 471-478.

9 Elizabeth J. Opila, "Oxidation and Volatilization of Silica Formers in Water Vapor," J. Am. Ceram. Soc., 86 (2003), 1238-48.

${ }^{10}$ Elizabeth J. Opila, "Variation of the Oxidation Rate of Silicon Carbide with Water-Vapor Pressure," J. Am. Ceram. Soc., 82 (1999), 625-36.

11 INL/MIS-12-25696 LWRS Fuel Development Plan.

${ }^{12}$ INL/EXT -12-27209.

${ }^{13}$ Physical Sciences, Inc., Andover, MA, USA.

${ }^{14}$ Saint-Gobain Ceramics, Niagara Falls, NY, USA.

15 Allegheny Technologies, Inc., Pittsburgh, PA, USA.

16 J. H. Baek, K. B. Park and Y. H. Jeon, "Oxidation kinetics of Zircaloy-4 and Zr-1 Nb-1Sn$0.1 \mathrm{Fe}$ at temperatures of 700-1200 ${ }^{\circ} \mathrm{C}, "$ J. Nucl.Mater. 335 (2004) 443-456.

17 J. H. Baek and Y. H. Jeon, "Steam oxidation kinetics of $\mathrm{Zr}-1.5 \mathrm{Nb}-0.4 \mathrm{Sn}-0.2 \mathrm{Fe}-0.1 \mathrm{Cr}$ and Zircaloy-4 at 900-1200 C," J. Nucl.Mater. 361 (2007) 30-40.

${ }^{18}$ K. Pettersson and Y. Haag, "Deformation and Failure of Zircaloy Cladding in a LOCA. Effects of Preoxidation and Fission Products on Deformation and Fracture Behavior. SKI project B23/78," Studsvik Energiteknik AB, STUDSVIK/K4-80/13, March 1980. 
${ }^{19}$ R. R. Biederman, et. al., “A Study of Zircaloy-4 - Steam Oxidation Kinetics,” EPRI NP-734 Final Report, April, 1978.

${ }^{20}$ E. D. Hindle and C. A. Mann, "An Experimental Study of the Deformation of Zircaloy PWR Fuel Rod Cladding Under Mainly Convective Cooling," Zirconium in the Nuclear Industry: Fifth Conference, 1980, Boston, MA, USA, ASTM STP 754, ASTM, pp. 284-302.

${ }^{21}$ S. Sagat, H. E. Sills, and J. A. Walsworth, "Deformation and Failure of Zircaloy Fuel Sheaths Under LOCA Conditions," Zirconium in the Nuclear Industry: Sixth International Symposium, 1982, Vancouver, Canada, ASTM STP 824, ASTM pp. 709-733.

22 T. Forgeron et. al., "Experiment and Modeling of Advanced Fuel Rod Cladding Behavior Under LOCA Conditions: A-B Phase Transformation Kinetics and EDGAR Methodology," Zirconium in the Nuclear Industry: Twelfth International Symposium, 1998, Toronto, Canada, ASTM STP 1354, ASTM pp. 256-278.

${ }^{23}$ J. H. Kim, et. al., "Embrittlement Behavior of Zircaloy-4 Cladding during Oxidation and Water Quench," Nuclear Engineering and Design, 235 (2005) 67-75.

${ }^{24}$ T. Furuta et. al., "Zircaloy Clad Fuel Rod Burst Test Behavior under Simulated Loss of Coolant Conditions in PWRs," J. Nucl. Sci. Technol., 15, (1978), 736-744. 